\title{
Convective drying kinetics of prickly pear seeds
}

\author{
S.Motri $^{1}$, A.Touil ${ }^{2}$, L. Hassini ${ }^{3}$, E. Bettaieb ${ }^{3}$, F.Zagrouba ${ }^{2}$. \\ ${ }^{I}$ High Institude of Technology Education, 1121 Zaghouan, Tunisia. \\ ${ }^{2}$ High Institute of Environment Science and Technology, Technopole Borj Cedria, 1003 Hammam-Lif, \\ Tunisia. \\ ${ }^{3}$ The Laboratory of Energy and Heat and MassTransfer (LETTM) (Faculty of Science of Tunis, Tunisia
}

\begin{abstract}
THE objective of this study was to investigate the drying kinetics of prickly pear seeds. Seeds were dried using a pilot scale convective dryer. Experiments were performed at air temperature of 45 and $70^{\circ} \mathrm{C}$ and at two relative humidity of 15 and $35 \%$ and air velocity of 1 and $2 \mathrm{~m} / \mathrm{s}$. The experimental drying data were fitted to different theoretical models to predict the drying kinetics. According to the results obtained, it was verified that the constant drying rate period was not detected in these drying experiments. The increase in the temperature and air velocity of drying air, increases the drying rate of seeds. The statistical parameters (correlation coefficients and standard errors) show that the Verna model was found to satisfactorily describe the air-drying curves of seeds. The characteristic drying curves of seeds was determined empirically by using the corresponding curve drying equations.
\end{abstract}

Keywords: Prickly pear seeds, Convective drying, Kinetics, mathematical model, drying air-conditions.

\section{Introduction}

Plant seeds are important sources of phytochemicals for nutritional, industrial, and pharmaceutical applications [1]. Moreover, the continued increase in world population and the ever increasing demand for oils necessitates the need to investigate new sources of oils [2]. For these reasons, new plant sources of phytochemicals, especially from underexploited seeds, have been investigated [1]. Opuntia ficus-indica fruit contains as many as 100-330 seeds, including viable and aborted seeds ([3]; [4]). Fresh prickly pear seeds are highly perishable and dehydratation is a useful means to increase the shelf life of seeds for further use. Sun drying is the most common method used to preserve agricultural products in most tropical countries. However this technique is extremely weather dependent and has the problems of contamination with dust, soil, sand particles and insects. Hot air drying of foods has low energy efficiency and a lengthy drying time during the techniques falling rate period. Heat transfer of food during conventional heating is limited, because of the low thermal conductivity of food materials in this period. Conventional (air) drying is the most frequently used dehydratation operation in food and chemical industry [5], due to its controllable conditions and less dependency on climatic conditions ([6]). Many researchers have been performed on drying of agricultural products (prickly pear peel, olive leaves, prickly pear fruit and cladodes) ([7] ; [8] and [9] ). No paper was found in the literature on the drying kinetics of prickly pear seeds.

The aim of this work is to study the convective drying kinetics of seeds. A convective dryer is used and the effect of air temperature, relative humidity and air velocity on the experimental drying of seeds kinetics is examined. A mathematical treatment of experimental data was then applied in order to fit the experimental variations of moisture ratios versus drying time by using seven empirical equations chosen in the literature and to determine the corresponding characteristic drying curve (CDC).

\subsection{Raw material}

\section{Material and methods}

Prickly pear seeds used in drying experiments were provided from prickly pear fruit (Opuntia ficus indica) grown in Knais, region of Monastir (Tunisia). Mature fruit samples were harvested in August 2012 and taken immediately to the laboratory where they manually peeled. Seeds were then separated using a separator. After bulk separation, the seeds were washed with water. The initial moisture content of all samples (varying between 0.9 and $1.5 \mathrm{~kg}$ per $\mathrm{kg}$ dry matter) were determined by the vacuum oven method at $105^{\circ} \mathrm{C}$ for $4 \mathrm{~h}$.

\subsection{Experimental set-up}

A convective dryer by the hot air was used for drying, which could be regulated to any desired drying air temperature, relative humidity and velocity of the drying air with high accuracy. Principal elements of this 
process are a centrifugal blower to aspire the ambient air, an electrical resistance air heating section ensuring the rise in the temperature of the air, heating control unit, a steam air moistening section, measurement sensors and a drying chamber. A balance of high precision located at the lower part of the drier. Temperature, air velocity and relative humidity inside the vein are adjusted and controlled using an automatic system of regulation. The measurement sensors and the data recording and controlling system coupled with a computer. The hot air orientation on the samples was vertical. The advantage of this type of flow is to offer optimum conditions for contact air-product and coefficient of significant transfer of heat. The experimental dryer was showed in Figure 1.

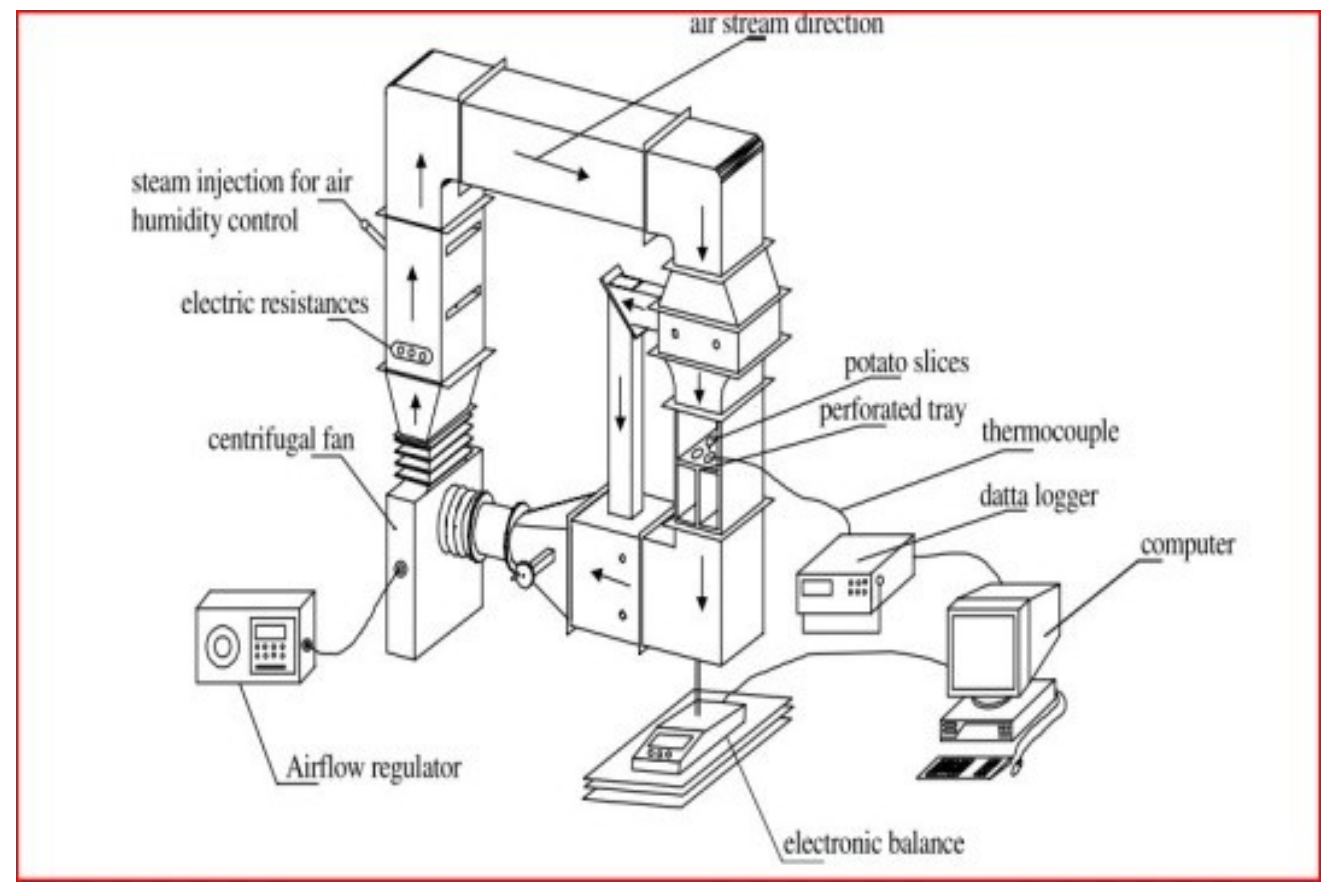

Fig.1. Overall layout of the experimental laboratory dryer (LETTM)

\subsection{Experimental drying procedure}

During drying in the convective dryer, the weight losses of the samples were measured at $10 \mathrm{~min}$ intervals. The drying tests were terminated when the mass of the samples reached a constant value. The air drying conditions tested are: the temperature, air velocity and relative humidity range from 45 to $70^{\circ} \mathrm{C}, 1$ to 2 $\mathrm{m} / \mathrm{s}$ and 15 to $35 \%$ respectively. $500 \mathrm{~g}$ of fresh seeds of prickly pear were used for each drying experiment.

Each experiment was done at least twice in order to check the reproductively of the drying curves. The dry mass of the product was determined after each experiment by vacuum oven method at $105^{\circ} \mathrm{C}$ for $4 \mathrm{~h}$. Our experiments are undertaken at different air conditions (Table 1).

Table 1: Drying air conditions during experimentation

\begin{tabular}{cccc}
\hline \hline Trial number & Temperature $\left({ }^{\circ} \mathrm{C}\right)$ & Relative Humidity $(\%)$ & $\begin{array}{c}\text { Air velocity } \\
(\mathrm{m} / \mathrm{s})\end{array}$ \\
\hline 2 & 70 & 15 & 1 \\
5 & 45 & 15 & 2 \\
6 & 70 & 15 & 2 \\
8 & 70 & 30 & 2 \\
\hline \hline
\end{tabular}

\subsection{Mathematical modelling of drying curves}

The Van Meel transformation [10] is applied for describing drying kinetics and determining the characteristic drying curves. Lopez et al., (2000) ([11]) and Kouhila et al., (2002) ([12]) used simply the initial moisture $\left(\mathrm{X}_{0}\right)$ and the equilibrium $\left(\mathrm{X}_{\mathrm{eq}}\right)$ moisture contents to normalize the moisture content obtained at any drying time $\left(\mathrm{X}_{\mathrm{t}}\right)$. The moisture ratio $(\mathrm{MR})$ of prickly pear seeds during drying experiments was calculated using the following equation: 


$$
M R=\frac{X_{t}-X_{e q}}{X_{0}-X_{e q}}
$$

Where $\mathrm{X}_{\mathrm{eq}}$ is determined from the desorption isotherms of prickly pear seeds and $\mathrm{X}_{\mathrm{t}}$ was deduced from product weight and initial moisture content and dry matter content of the seeds.

The dimensionless drying rate (f) was also determined for each drying experiment as following:

Where $-\left(\frac{\mathrm{d} M \mathrm{R}}{\mathrm{dt}}\right)_{0}$ is the initial drying rate.

$$
f=\frac{-\frac{d M R}{d t}}{\left(-\frac{d M R}{d t}\right) 0}
$$

The values of $\mathrm{X}_{\mathrm{eq}}$ are relatively little compared to those of $\mathrm{X}_{\mathrm{t}}$ or $\mathrm{X}_{0}$, the error involved in the simplification is negligible ([13)], and thus moisture ratio was calculated as:

$M R=\frac{X t}{X 0}$

The experimental variations of moisture ratios versus drying time $(\mathrm{MR}=\mathrm{f}(\mathrm{t}))$ of prickly pear seeds were described by using seven models (Table 2) chosen from the most used equations in literature to describe the thin layer drying kinetics of agricultural products ([7]; [14]; [15]).

Table 2: Drying curve models used

\begin{tabular}{clcl}
\hline $\begin{array}{c}\mathbf{N}^{\circ} \\
\text { model }\end{array}$ & \multicolumn{1}{c}{ Model name } & \multicolumn{1}{c}{ Model } & \multicolumn{1}{c}{ Reference } \\
\hline 1 & Lewis & $\mathrm{MR}=\exp ^{(-k t)}$ & Bruce (1985) [16] \\
2 & Page & $\mathrm{MR}=\exp ^{\left(-k t^{a}\right)}$ & Page (1949) [17] \\
3 & Modified Page-I & $\mathrm{MR}=\exp ^{\left(-(k t)^{a}\right)}$ & White et al., (1981) [18] \\
4 & Henderson and Pabis & $\mathrm{MR}=a \exp ^{\left(-k t^{b}\right)}$ & Henderson and Pabis (1961) \\
5 & Logarithmic & $\mathrm{MR}=a \exp ^{(-k t)}+c$ & {$[19]$} \\
6 & Two term exponential & $\mathrm{MR}=a \exp ^{(-k t)}+(1-a) \exp ^{(-k a t)}$ & $\begin{array}{l}\text { Sharf-Elden and Pehlivan (2002) } \\
\text { Shal., (1980) }\end{array}$ \\
7 & Verna et al. & $\mathrm{MR}=a \exp ^{(-k t)}+(1-a) \exp ^{(-g t)}$ & Verna et al. (1985) [22] \\
\hline
\end{tabular}

The corresponding experimental characteristic drying curves given by plotting the drying rates (f) as a function of moisture ratios were also described by the mathematical correlation giving the best fit of experimental data. A non linear optimization method, using the computer program "CurveExpert Professional 1.5.0" was used to determine the parameters of the used equations.

The parameters of each model were determined by minimizing the difference between calculated and experimental data. The adequacies of the models were evaluated by using two statistical parameters: the standard error (S) and the correlation coefficient (r). These parameters are defined as following:

$$
\begin{aligned}
& S=\sqrt{\frac{\sum_{i=1}^{n_{\text {exp.data }}\left(E_{x p}-\text { Cali }^{2}\right.}}{n_{\text {exp.data }}-n_{\text {param }}}} \\
& r=\sqrt{1-\frac{\sum_{i=1}^{n_{\text {exp.data }}}\left(E x p_{i}-\text { Cali }^{2}\right.}{\sum_{i=1}^{n_{\exp \text { data }}}\left(E x p_{i}-E x p i\right)^{2}}}
\end{aligned}
$$

Where "Cal" is the value of the moisture ratio or of the drying rate (f) calculated by using the tested model, "Exp" is the experimental value of the moisture ratio or of the drying rate, $\mathrm{n}_{\text {param }}$ is the number of parameters of the particular model and $\mathrm{n}_{\text {exp }}$. data is the number of experimental points.

\subsection{Determination of the drying curves}

\section{Results and discussion}

Figures 2 and 3 shows, respectively, the variations of the moisture ratios versus drying time (Fig.2) and the drying rates versus drying time (Fig. 3) of seeds obtained at different conditions. The constant rate period (phase 1) is absence in the convective drying of seed. The absence of phase 1 is due to the difficulty of 
the capillary migration of water from the heart to the wet rigid surfaces of prickly pear seeds, which requires a significant heat input to vaporize the water in the within the seed and the discharging in the vapour state. The drying process took place in the falling rate period. Drying rate decreases continuously with diminishing moisture ratio. These results are in agreement with the observation of earlier researchers ([23]). Bimbenet et al., (1984) ([23]) noted that the constant rate period (phase 1) is not observed in some biological products. Drying during the falling rate period is so governed by water diffusion in the solid. This is a complex mechanism involving water in both liquid and vapour states, which is very often characterised by a so-called 'effective diffusivity' ([24]). These results indicated that diffusion is the most likely physical mechanism governing moisture movement in the seed of prickly pear.

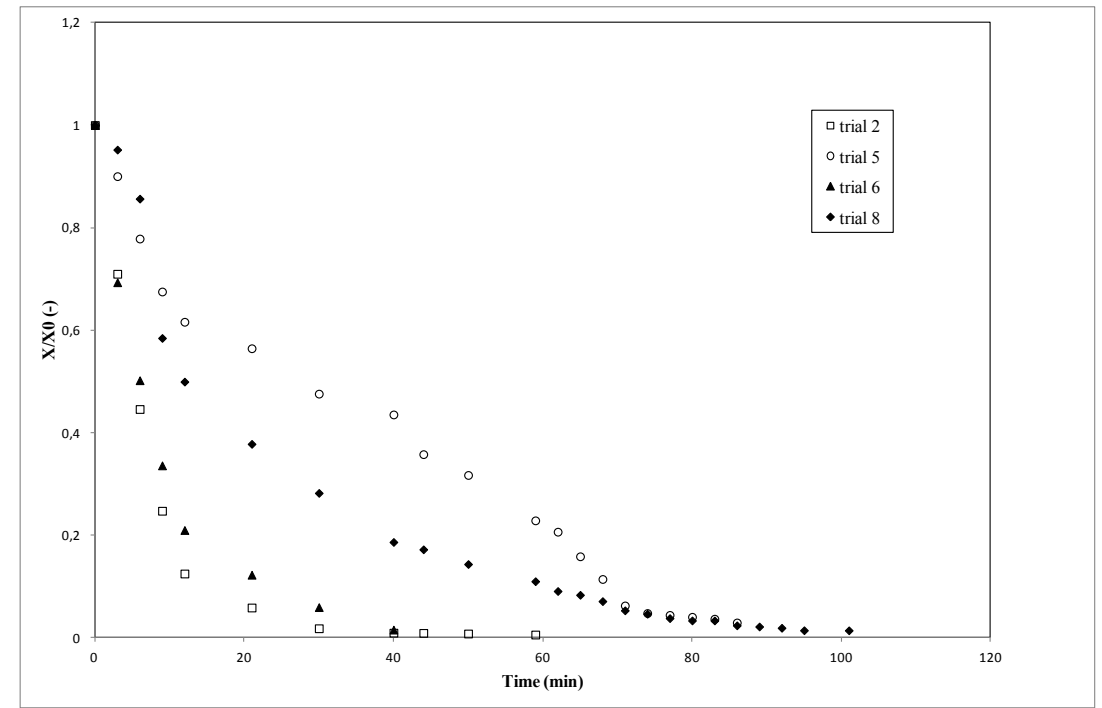

Fig.2 : Experimental moisture ratios versus drying time

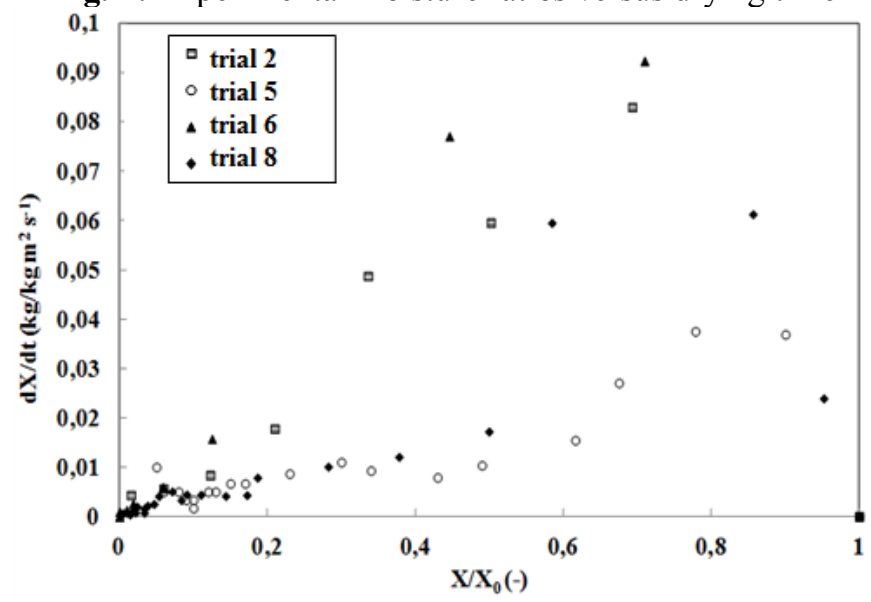

Fig.3: Experimental drying rates versus moisture ratios

\section{1. 1. Influence of drying temperature}

Figure 4 shows that the drying rates increased with the increase of air temperature. In fact, a higher drying air temperature produces a higher drying rate of the seeds and accelerates the moisture migration. The drying rate is highest at the first of drying for 45 and $70^{\circ} \mathrm{C}$ and decreases with time. This is a result of low internal resistance of moisture at the beginning of drying. Therefore, as noted in paragraph 3.1., the wet rigid surfaces of prickly pear seeds induce a difficulty of the capillary migration of water from the heart to the surface. This phenomena requires a significant heat input to vaporize the water in the within the seed and the discharging in the vapour state. As the drying progressed, more energy was required to break the molecular bond of the moisture and since constant energy was supplied, it took longer time to break, therefore drying rate decreased.

So that, higher temperature implies larger driving force for heat transfer (([25]; ([26]). It also accelerates the drying process, as the temperature provides a larger water vapour pressure deficit ([27]). The higher the temperature the bigger is the difference between the saturated and partial pressure of water vapour 
in the drying-air, which is one of the driving forces for drying; as there is a maximum amount of water (saturation) that air can hold at a given temperature. Moreover, the amount of free water present at the start is very important, since the rate of water removal is higher during this phase ([28]). As the drying proceeds, the free water present decreases quite rapidly, so that at the final stages, water was hardly available and the drying becomes very slow. Thus, air temperature is known to be the main parameter influencing air drying of agriculture products, the same results were observed by Touil et al., (2010) ([24]) for the drying kinetics of prickly pear fruit and cladodes. These evolutions of drying curves are characteristic of drying kinetics of biological products and are also observed by other authors ([7]; ([29]).

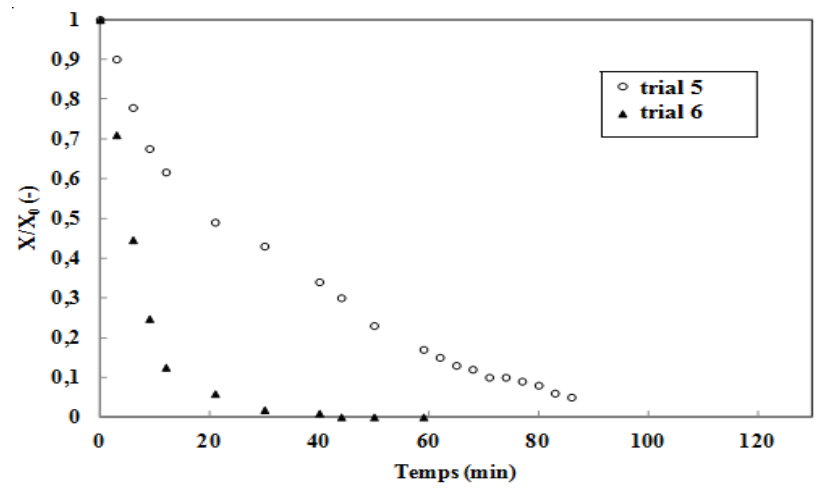

Fig.4 : Influence of temperature on the moisture ratios

\section{1. 2. Influence of the relative humidity of the air}

Curves for trials 6 and 8 show the effect of drying-air relative humidity on the drying behaviour of seeds. The moisture ratio of the samples decreased continually with drying time. As expected, decrease in the relative humidity of drying air reduces the time required to reach any given level of moisture ratio since the mass transfer increases. In other words, at low relative humidity of air the transfer of heat and mass is high and water loss is excessive. However, in our case, the times were not varied a lot when the RH was increased from 15 to $30 \%$, and the effect of air-humidity on the acceleration of the drying progress is considered, in general, as much lower than that of air-temperature. Same conclusion is reported by Krokida et al., (2003) ([30]); Saeed et al., (2006) ([31]); and Tarigan et al., (2007) ([32]).

\section{1. 3. Influence of the velocity of the air}

Increasing the velocity of air from 1 to $2 \mathrm{~m} / \mathrm{s}$ causes a reduction in drying time. This is seen by comparing trials 6 and 2. Air velocity seems to have a less important effect than the drying air temperature, as observed by Lahsasni et al., (2004) ([7]) for the drying kinetics of prickly pear fruit (O. ficus-indica). These results are in good agreement with theory. Dagunet (1985) ([33]) explains this phenomenon by providing the drying rate as a function of the transfer coefficient of water vapour in the air increases with the speed of flow of the air. This parameter therefore exerts a significant influence on the rate of drying.

\subsection{Modelling of the drying curves}

\subsubsection{Fitting of the variations of moisture ratios versus drying time}

Seven drying models have been used to describe drying curves. The model number, constant model or coefficient and correlation coefficient of these models used for moisture ratio change with time are presented in Table 3. It is obvious that in the tables above the average regression coefficient of the seventh model (Verna et al., 1985) ([22]) is higher and standard error value is lower than the values of the other model. Therefore, the model of Verna et al., 1985, can be proposed to evaluate the moisture ratio of prickly pear seeds for the range of the drying temperature and time in this study (Fig.5).

Table 3: Models parameters

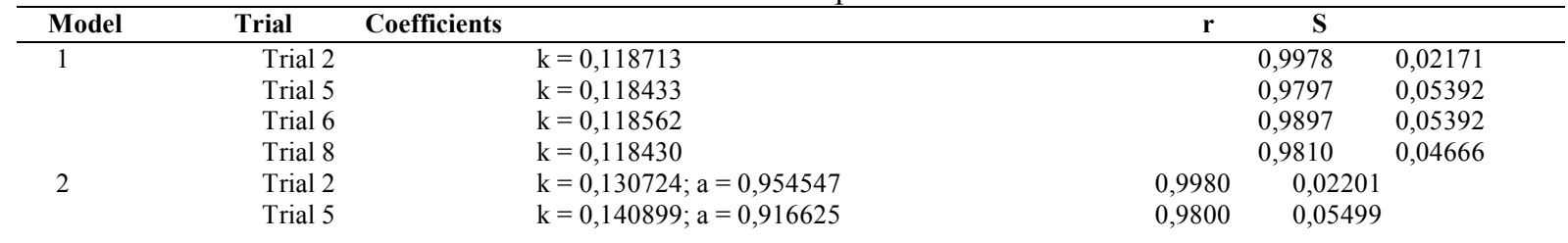




\begin{tabular}{|c|c|c|c|c|}
\hline & Trial 6 & $\mathrm{k}=0,140899 ; \mathrm{a}=0,916625$ & 0,9800 & 0,05498 \\
\hline & Trial 8 & $\mathrm{k}=0,141379 ; \mathrm{a}=0,914923$ & 0,9813 & 0,04723 \\
\hline \multirow[t]{4}{*}{3} & Trial 2 & $\mathrm{k}=0,118653 ; \mathrm{a}=0,954547$ & 0,9980 & 0,02202 \\
\hline & Trial 5 & $\mathrm{k}=0,117895 ; \mathrm{a}=0,916621$ & 0,9800 & 0,05498 \\
\hline & Trial 6 & $\mathrm{k}=0,117895 ; \mathrm{a}=0,916621$ & 0,9800 & 0,05499 \\
\hline & Trial 8 & $\mathrm{k}=0,117864 ; \mathrm{a}=0,914626$ & 0,9813 & 0,04723 \\
\hline \multirow[t]{4}{*}{4} & Trial 2 & $\mathrm{k}=0,13198 ; \mathrm{a}=1,002 ; \mathrm{b}=0,951$ & 0,9980 & 0,02319 \\
\hline & Trial 5 & $\mathrm{k}=0,14422 ; \mathrm{a}=1,006 ; \mathrm{b}=0,909$ & 0,9800 & 0,05656 \\
\hline & Trial 6 & $k=0,14423 ; a=1,0063 ; b=0,909$ & 0,9801 & 0,05657 \\
\hline & Trial 8 & $\mathrm{k}=0,14484 ; \mathrm{a}=1,0065 ; \mathrm{b}=0,906$ & 0,9813 & 0,04818 \\
\hline \multirow[t]{4}{*}{5} & Trial 2 & $\mathrm{k}=0,1167 ; \mathrm{a}=0,9987 ; \mathrm{c}=-0,0041$ & 0,9979 & 0,02375 \\
\hline & Trial 5 & $\mathrm{k}=0,1304 ; \mathrm{a}=0,9676 ; \mathrm{c}=0,03776$ & 0,9868 & 0,04592 \\
\hline & Trial 6 & $\mathrm{k}=0,1304 ; \mathrm{a}=0,9677 ; \mathrm{c}=0,0378$ & 0,9869 & 0,04593 \\
\hline & Trial 8 & $\mathrm{k}=0,1274 ; \mathrm{a}=0,9741 ; \mathrm{c}=0,0291$ & 0,9869 & 0,04039 \\
\hline \multirow[t]{4}{*}{6} & Trial 2 & $\mathrm{k}=0,159733 ; \mathrm{a}=0,536695$ & 0,9981 & 0,02140 \\
\hline & Trial 5 & $\mathrm{k}=0,179625 ; \mathrm{a}=0,465009$ & 0,9803 & 0,05450 \\
\hline & Trial 6 & $\mathrm{k}=0,179625 ; \mathrm{a}=0,465010$ & 0,9804 & 0,05451 \\
\hline & Trial 8 & $\mathrm{k}=0,179974 ; \mathrm{a}=0,463810$ & 0,98165 & 0,04682 \\
\hline \multirow[t]{4}{*}{7} & Trial 2 & $\mathrm{k}=0,0782 ; \mathrm{a}=0,5349 ; \mathrm{g}=0,1979$ & 0,9980 & 0,02255 \\
\hline & Trial 5 & $\mathrm{k}=-0,0201 ; \mathrm{a}=0,010 ; \mathrm{g}=0,12278$ & 0,9877 & 0,04455 \\
\hline & Trial 6 & $\mathrm{k}=0.08523 ; \mathrm{a}=0,4688 ; \mathrm{g}=0,1615$ & 0,9982 & 0,02227 \\
\hline & Trial 8 & $\mathrm{k}=0,00401 ; \mathrm{a}=0,0395 ; \mathrm{g}=0,129$ & 0,9879 & 0,04028 \\
\hline
\end{tabular}

A comparison between the experimental and calculated (Verna equation) variations of moisture ratios versus time of prickly pear seeds obtained at different conditions is illustrated in Figure 6. These curves show the adequacy between calculated and experimental drying curves.

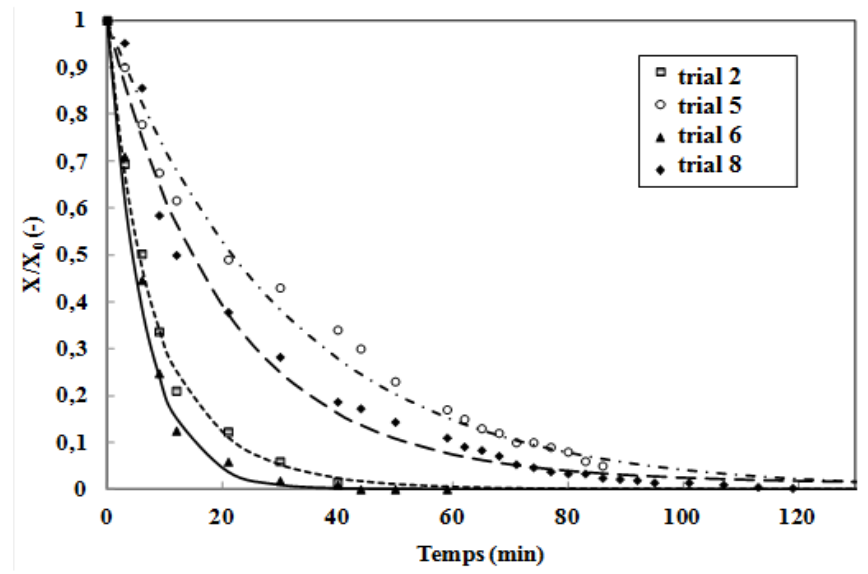

Fig.5: Verna model fitted to the drying data

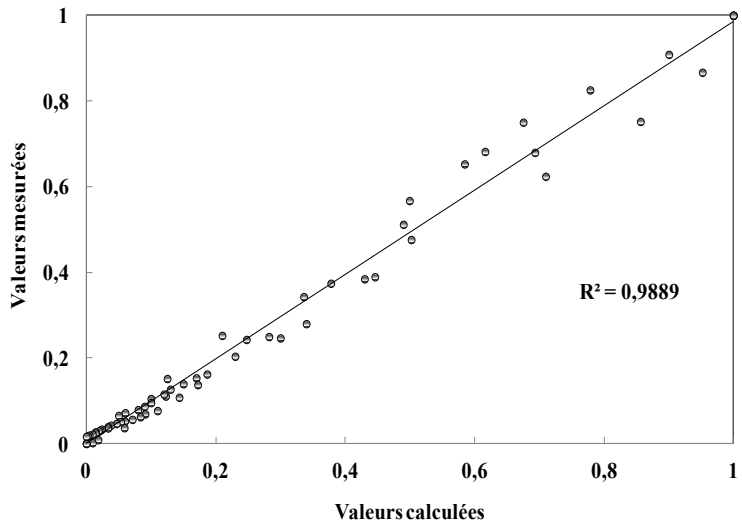

Fig.6: Comparison of experimental data with values predicted by Verna model

\subsubsection{Determination of the characteristic drying curve}

The variations of the experimental dimensionless drying rates versus experimental moisture ratios $\left(X^{*}=\frac{X_{t}-X_{e q}}{X_{0}-X_{e q}}\right)$ obtained at different conditions for prickly pear seeds were fitted by using different 
mathematical correlations. Polynomial equation (order 4) was found to fit the best the experimental data. The polynomial equation obtained is:

$\frac{X}{X_{2}}=-9,553 X^{* 4}+14,851 X^{* 3}-8,639 X^{* 2}+3,330 X^{*}+0,132$.

Figure 7 shows a comparison between experimental and calculated values of the drying rates versus moisture ratio.

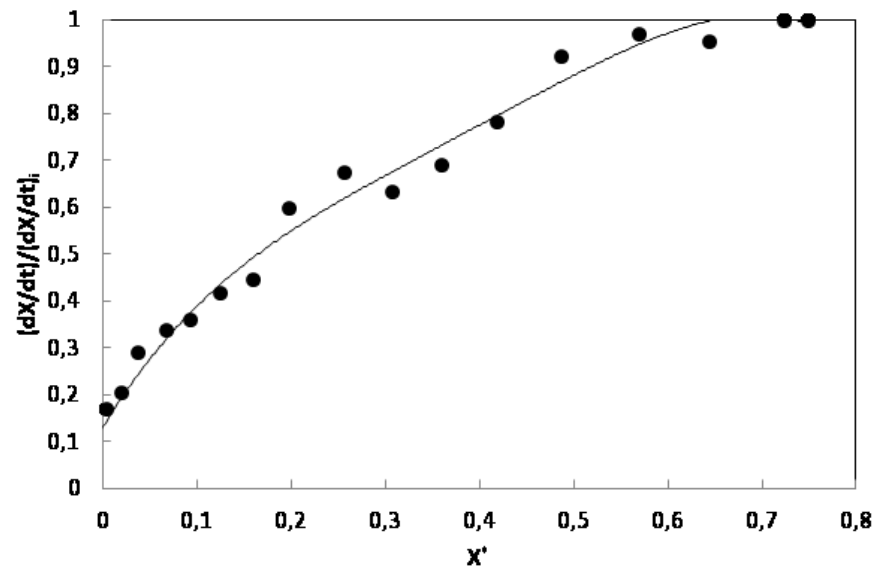

Fig.7: Variation of the dimensionless drying rate versus moisture ratio of seeds, Dots: experimental data, Line: calculated value by using the polynomial equation.

\section{Conclusion}

From the experimental drying curves obtained, the drying air temperature was found to be the main factor influencing the drying kinetics. A constant drying rate period was not detected in these drying experiments. In order to explain the drying behaviour of prickly pear seeds, seven different drying models in the literature were compared with their regression coefficient and standard error values. The Verna equation drying model was found satisfying to describe the convective drying curves of prickly pear seeds. The characteristic drying curves of seeds was determined.

\section{References}

[1]. Tlili, N., Munné-Bosch, S., Nasri, N., Saadaoui, E., Khaldi, A., \& Triki, S. (2009). Fatty acids, tocopherols and carotenoids from seeds of Tunisian caper. J. Food Lipids, 16, 452-464.

[2]. Omode, A.A., Fatoki, O.S., \& Olaogun, K.A. (1995). Physicochemical properties of some underexploited and nonconventional oil seeds. J.Agric.Food Chem, 43, 2850-2853.

[3]. Barbera, G. and Inglese, P. (1993). La coltura del Ficodindia. Edagricole, Calderini,Bologna, pp 189.

[4]. Weiss, J., Nerd, A., \& Mizrahi, J. (1993). Vegetative parthenocarpy in the cactus pear Opuntia ficus indica (L) Mill. Ann.Bot., 72, 521526.

[5]. Nicoleti, J.F., Telis-Romero, J., \& Telis, V.R.N. (2001). Air-drying of fresh and osmotically pre-treated pineapple slices : fixed air temperature versus fixed temperature drying kinetics. Drying technology, 19, 2175-2191.

[6]. Lertworasiriku, S and Tipuwan, Y. (2008). Moisture content and water activity prediction of semi-finished cassava crackers from drying process with artificial neural network. Journal of food engineering, 84, 65-74.

[7]. Lahsasni, S., Kouhila, M., Mahrouz, M., Idlimam, A \& Jamali, A. (2004). Thin layer convective solar drying and mathematical modelling of prickly pear peel (opuntia ficus indica). Energy, 29: 211-224.

[8]. Boudhrioua, N., Kouhila, M., \& Kechaou, N. (2007). Experimental and mathematical investigations of convective solar drying of four vareties of olive leaves. Food and bioproduct processing.

[9]. Touil, A., Chemkhi, S., \& Zagrouba, F. (2010). Modeling of the drying kinetics of opuntia ficus indica fruits and cladodes. International journal of food engineering.

[10]. Van Meel, D.A. (1958). Adiabatic convection batch drying with recirculation of air. Chem Eng Sci, 9, 36-44.

[11]. Lopez, A., Iguaz, A., Esnoz, A., \& Virseda, P. (2000). Thin-layer drying behaviour of vegetable wastes from wholesale market. Drying Technol, 18(4-5), 995-1006.

[12]. Kouhila, M., Kechaou, N., Otmani, N., Fliyou, M. \& Lahsasni, S. (2002). Experimental study of sorption isotherms and drying kinetics of Moroccan Eucalyptus globulus. Drying Technol, 20(10), 2027-2039.

[13]. Aghbashlo, M., Kianmehr, M.H., \& Samimi-Akhljahani, H. (2008). Influence of drying conditions on the effective moisture diffusivity, energy of activation and energy consumption during the thin-layer drying of barberries fruit. Energy conversion and management, 49, 2865-2871.

[14]. Midilli, A., Kucuk, H., \& Yapar, Z. (2002), A new model for single layer drying. Drying technology.

[15]. Yaldiz, O., Ertekin, C., \& Uzun, H.B. (2001), Mathematical modelling of thin layer solar drying of sultana grapes, Energy, 26, $457-465$.

[16]. Bruce, D.M. (1985). Exposed-layer barley drying, three models fitted to new data up to $150{ }^{\circ}$ C. Journal of Agricultural Engineering Research, 32, 337-347. 
[17]. Page, G.E. (1949). Factors influencing the maximum rates of air drying shelled corn in thin layers. M.S. Thesis. Department of Mechanical Engineering, Purdue University, USA.

[18]. White, G.M., Ross, I.J., \& Poneleit, C.G. (1981). Fully exposed drying of popcorn. Transactions of the ASAE, 24, 466-468.

[19]. Henderson, S.M. and Pabis, S. (1961). Grain drying theory. II. Temperature effects on drying coefficients. Journal of Agricultural, 44, $1111-1122$.

[20]. Togrul, I.T., \& Pehlivan, D. (2002). Mathematical modelling of solar drying of apricots in thin layers. Journal of Food Engineering, 55, $209-216$.

[21]. Sharaf-elden, Y.I., Blaisdell, J.L., \& Hamdy, M.Y. (1980). A model for ear corn drying. Transactions of the ASAE, 5, 1261-1265.

[22]. Verma, L.R., Bucklin, R.A., Endan, J.B., \& Wratten, F.T. (1985). Drying effects of drying air parameters on rice drying models. Transactions of the ASAE, $\mathbf{8 5}, 296-301$.

[23]. Bimbenet, J. J., Daudin, J.D., \& Wolff, E. (1984). Air drying kinetics of biological particle. Proceeding of the fourth International Drying Symposium, Kyoto.

[24]. Al hodali, R. (1997). Numerical simulation of an agricultural foodstuffs drying unit using solar energy and adsorption process. These de Ph.D, Université Libre de Bruxelles, Belgique.

[25]. Methakhup, S., Chiewchan, N., \& Davahastin, S. (2005). Effects of drying methods and conditions on drying kinetics and quality of Indian gooseberry flake. Swiss Society of Food Science and Technology, 38, 579-587.

[26]. Nimmol, C., Devahastin, S., Swasdisevi, T., \& Saponronnarit, S. (2007). Drying of banana slices using combined low-pressure superheated steam and far-infrared radiation. Journal of Food Engineering, 81, 624-633.

[27]. Prabhanjan, D. G., Ramaswamy, H. S., \& Raghavan, G. S. V. (1995). Microwave-assisted convective air drying of thin layer carrots. Journal of Food Engineering, 25, 283-293.

[28]. Guiné, R. P. F., Ferreira, D. M. S., Barroca, M. J. \& Goncalves, F. M. (2007). Study of the drying kinetics of solar-dried pears. Biosystems Engineering, 98, 422-429.

[29]. Ait Mohamed, L., Kouhila, M., Jamali, A., Lahsasni, S., Kechaou, N. \& Mahrouz, M. (2005). Single layer solar drying behaviour of Citrus aurantium leaves under forced convection. Energy Convers Manage, 46, 1473-1483.

[30]. Krokida, M. K., Karathanos, V. T., Maroulis, Z. B., \& Marinos-Kouris, D. (2003). Drying kinetics of some vegetables. Journal of Food Engineering, 59, 391-403.

[31]. Saeed, I. E., Sopian, K., \& Zainol Abidin, Z. (2006). Drying kinetics of roselle: dried in a constant temperature and humidity chamber. Proc. SPS 2006. Edited by Muchtar. 29-30 August. Permata, Bangi, S.D.E., Malaysia, 143-148.

[32]. Tarigan, E., Prateepchaikul, G., Yamsaengsung, R., Sirichote, A., \& Tekasakul, P. (2007). Drying characteristics of unshelled kernels of candle nuts. Journal of Food Engineering, 79, 828-833.

[33]. Dagunet, M. (1985). Les séchoirs solaires: théorie et pratique publication de l'UNESCO, Paris, France. 